\title{
Fatty foods and calorie intake of cardiovascular patients
}

\begin{abstract}
Background: Cardiovascular diseases are rapidly spreading almost all parts of the planet. Faulty food habit, high calorie intake and sedentary life style are responsible for this gloomy picture.

Objective: To observe the effect of fatty foods and calorie intake on cardiovascular patients was aim of this study.
\end{abstract}

Material and methods: This cross-sectional observational study was undertaken among 100 cardiovascular patients of 25-79years old in different selected areas in the Dhaka city during the period of August 2015 to January 2016.

Results: About $15.7 \%$ respondents removed visible fat of meat and $84.3 \%$ didn't remove visible fat. Moreover $47.1 \%$ respondents consumed oily foods about 2-3 times a day. Data shows $19.8 \%$ were in best LDL range, $41.6 \%$ were in near optimal range, $28.7 \%$ were in borderline high range, $8.9 \%$ were in high range and $1 \%$ were in very high range. Result shows $13.9 \%$ were in desirable TG range, $48.5 \%$ were in borderline high range, $37.6 \%$ were in high range. About $28.7 \%$ had taken below $1200 \mathrm{kcal}$ followed by $1200-1499 \mathrm{kcal} 24.8 \%, 1500-1799 \mathrm{kcal} 29.7 \%$ and $1800-2099 \mathrm{kcal} 16.8 \%$.

Conclusion: LDL and TG intake are still high among study subjects. Health awareness programme can be constituted immediately.

Keywords: fatty foods, calorie intake, cardiovascular patients
Volume 8 Issue 5 - 2018

Refat Mahtarin, Nazia Ahmed, Wahida Anmona

Masters of Science in Food and Nutrition, Dhaka University, Bangladesh

Correspondence: Refat Mahtarin, Masters of Science in Food and Nutrition, Home Economics College, Dhaka University, Bangladesh, Email cn_bihs_2012@yahoo.com

Received: August 30, 20I8 | Published:September 05, 2018

\section{Introduction}

Death due to cardiovascular diseases (CVDs) is high (80\%) in low and middle-income countries. ${ }^{1}$ Food habit, food system and policy solution are changing globally. ${ }^{1}$ Besides diet is considered as major factor in order to rising tendency of non-communicable diseases particularly CVD components. ${ }^{2}$ Poor quality diets are high in refined grains and added sugars, salt, unhealthy fats and animal-source foods; and low in whole grains, fruits, vegetables, legumes, fish and nuts. They are often high in processed food products - typically packaged and often ready to consume - and light on whole foods and freshlyprepared dishes. According to the American Heart Association one adult should consume a low-fat diet of $55 \%$ of total calories from carbohydrates, $30 \%$ from fat, and $15 \%$ from protein, with cholesterol restricted to $<300 \mathrm{mg} /$ day to prevent cardiovascular diseases risk. ${ }^{3}$ This paper is an attempt to explore fatty foods and calorie consumption among cardiovascular patients.

\section{Methodology}

It was a cross sectional observational study carried out among 100 cardiovascular patients of 25-79 years old in different selected areas in the Dhaka city during the period of August 2015 to January 2016. The study subjects were from National Institute of Cardiovascular Diseases and Shaheed Suhrawardy Medical College Hospital after approval of institutional heads.

\section{Development of tools}

Development of the questionnaire: A semi-structured questionnaire was developed to collect data through face-to-face interview with the respondents. This questionnaire was developed to obtain the recent information regarding the personal information, household information, socio-economic information.

\section{Assessment of fat and calorie rich dietary intake}

i. Fat and calorie rich dietary practices of the respondents were assessed through 24-hour recall method

ii. There was about 25 questions in the questionnaire regarding intake of fatty food and calorie rich diet, green leafy vegetables, fruits, cereals, salt, salty food, sugar, etc

iii. By using 24-hour recall method, dietary history and frequency of fatty food intake among the cardiovascular patients were assessed

iv. In order to estimate the amount of usual fat and calorie intake, the fractional portion size of each food consumed daily was multiplied by its fat and calorie content

v. The value was then summed up to obtain an estimate of an individual's total daily fat and calorie intake

Data verification: Questionnaires were checked each day after interviewing and again these were carefully checked after completion of all data collection and coded before entering into the computer. The data was edited if there was any discrepancy (double entry, wrong entry etc).

Statistical analysis: All of the statistical analysis and other data processing were done by using SPSS 20 Windows Program. For tabular, charts and graphical representation Microsoft Word and Microsoft Excel were used. 
Ethical implication: No data or any information was collected without permission of the patient. Participation in this research was fully voluntary. The respondents were remained entirely free to withdraw their participation at any stage or at any time of the study. Written informed consent was taken from each patient. Prior to consent they were explained the aim and purpose of the research. Confidentiality was assured and anonymity was maintained; no participants were identified in any report or publication under this study.

Results (Table 1-6) and (Figures 1-8)

Table 1 Age distribution of the study population $(n=100)$

\begin{tabular}{lll}
\hline Age group (Years) & Frequency & Percentage \\
\hline $25-29$ & 7 & 7 \\
$30-45$ & 32 & 32 \\
$46-65$ & 51 & 51 \\
$66-80$ & 10 & 10 \\
Total & 100 & 100 \\
\hline
\end{tabular}

It shows that half of the respondents belonged to 46-65years of age followed by $32 \%$ from $30-45$ years, $10 \%$ from $66-80$ years and $7 \%$ from $25-29$ years.

Table 2 Distribution of the population by gender $(\mathrm{n}=100)$

\begin{tabular}{lll}
\hline Category & Frequency & Percentage \\
\hline Male & 87 & 87 \\
Female & 13 & 13 \\
Total & 100 & 100 \\
\hline
\end{tabular}

It shows that $87 \%$ of the respondents were male and $13 \%$ were female.

Table 3 shows that labor, service holder, business, teacher and housewife were $25 \%, 18 \%, 15 \%, 14 \%$ and $13 \%$ respectively.

\begin{tabular}{lll}
\hline Category & Frequency & Percentage \\
\hline Labor & 25 & 25 \\
Business & 15 & 15 \\
Garments worker & 4 & 4 \\
Retired & 8 & 8 \\
Service holder & 18 & 18 \\
Housewife & 13 & 13 \\
Teacher & 14 & 14 \\
Student & 3 & 3 \\
Total & 100 & 100 \\
\hline
\end{tabular}

Table 3 shows that labor, service holder, business, teacher and housewife were $25 \%, 18 \%, 15 \%, 14 \%$ and $13 \%$ respectively.

Table 4 Distribution of the population by educational qualification $(n=100)$

\begin{tabular}{lll}
\hline Category & Frequency & Percentage \\
\hline Below SSC & 23 & 23 \\
SSC & 21 & 21 \\
HSC & 17 & 17
\end{tabular}

\begin{tabular}{lll}
\hline Category & Frequency & Percentage \\
\hline Graduate & 20 & 20 \\
Post-graduate & 19 & 19 \\
Total & 100 & 100 \\
\hline
\end{tabular}

This table shows the educational qualification of the respondents. It was found that $23 \%$ of the study population had educational qualification below SSC followed by $21 \%$ SSC, $17 \%$ HSC, $20 \%$ Graduate and $19 \%$ postgraduate.

Table 5 Distribution of the population by income $(\mathrm{n}=100)$

\begin{tabular}{lll}
\hline Category in BDT & Frequency & Percentage \\
\hline$<10000$ & 15 & 15 \\
$10000-20000$ & 33 & 33 \\
$21000-35000$ & 40 & 40 \\
$>36000$ & 12 & 12 \\
Total & 100 & 100 \\
\hline
\end{tabular}

The table 5 shows that $15 \%$ respondents had monthly income below 10000 BDT followed by $33 \%$ had $10000-20000$ BDT, $40 \%$ had 21000-35000 BDT and $12 \%$ had $>36000$ BDT as well.

Table 6 Fatty foods intake and heart diseases

\begin{tabular}{llll}
\hline $\begin{array}{l}\text { Fat } \\
\text { consumption } \\
\text { range (\%) }\end{array}$ & Frequency & $\begin{array}{l}\text { No. of people } \\
\text { suffering from } \\
\text { heart disease }\end{array}$ & $\begin{array}{l}\text { Percentage } \\
\text { of people } \\
\text { suffering from } \\
\text { heart disease }\end{array}$ \\
\hline$\geq 30$ & 56 & 31 & 54.36 \\
$<30$ & 44 & 24 & 50.54 \\
\hline
\end{tabular}

About $54.36 \%$ consumed $\geq 30$ percent fat and suffered from heart diseases whereas $\leq 30$ percent consumed fat respondents had 50.54 percent Heart Diseases

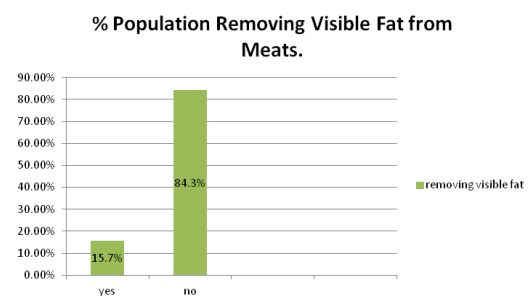

Figure 1 Distribution of participants by removing visible fat of meat or chicken $(\mathrm{n}=100)$

Figure shows $15.7 \%$ respondents removed visible fat of meat and $84.3 \%$ didn't remove visible fat.

$$
\begin{gathered}
\text { \% Population Oily Foods } \\
\text { Consumption }
\end{gathered}
$$
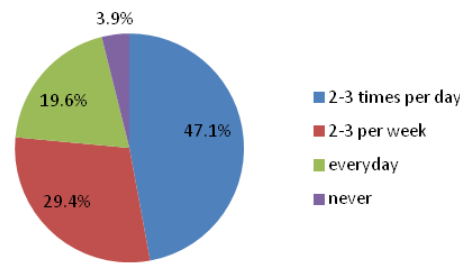

Figure 2 Distribution of participants by consuming oily foods $(\mathrm{n}=100)$. 
This pie chart shows $47.1 \%$ respondents consumed oily foods about 2-3 times a day, $29.4 \%$ consumed 2-3 times per week, $19.6 \%$ consumed every day and $3.9 \%$ never consumed.

\% Population Presently Suffering from Diseases

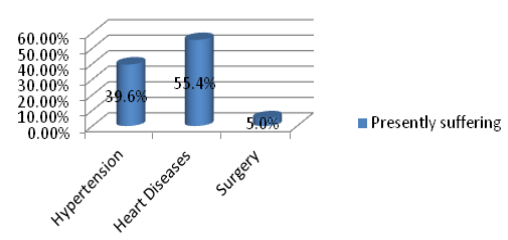

Figure 3 Distribution of participants by suffering from what presently $(\mathrm{n}=100)$.

Data represented in above figure shows $39.6 \%$ respondents suffered from hypertension, $55.4 \%$ heart diseases and $5.0 \%$ surgical procedure.

\section{By Cholesterol} (mg/dl) Level.

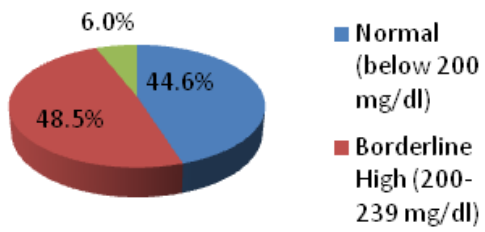

Figure 4 Distribution of participants by Cholesterol $(\mathrm{n}=100)$

Figure shows $44.6 \%$ respondents were in normal cholesterol range, $48.5 \%$ were in borderline high cholesterol range and $6 \%$ were in high cholesterol range.

$$
\text { By HDL (mg/dl) }
$$

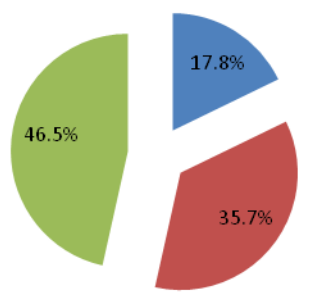

$$
\begin{aligned}
& \text { Best (above } 60 \\
& \mathrm{mg} / \mathrm{dl}) \\
& \text { Better }(50-59 \\
& \mathrm{mg} / \mathrm{dl}) \\
& \begin{array}{l}
\text { Poor (below } 40 \\
\mathrm{mg} / \mathrm{dl})
\end{array}
\end{aligned}
$$

Figure 5 Distribution of participants by $\operatorname{HDL}(n=100)$.

Data represented in above figure shows $17.8 \%$ respondents were in best HDL range, $35.7 \%$ were in better HDL range and $46.5 \%$ were in poor range

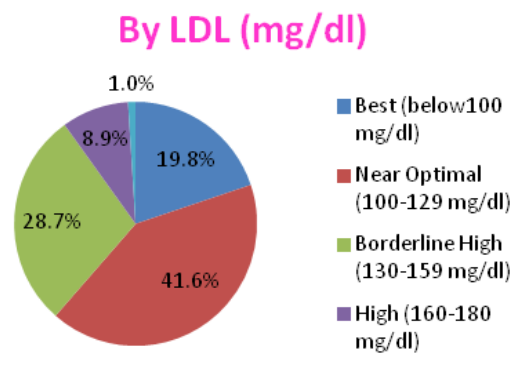

Figure 6 Distribution of participants by LDL $(n=100)$.

Data represented in above figure shows $19.8 \%$ were in best LDL range, $41.6 \%$ were in near optimal range, $8.7 \%$ were in borderline high range, $8.9 \%$ were in high range and $1 \%$ were in very high range.

\section{By TG (mg/dl)}
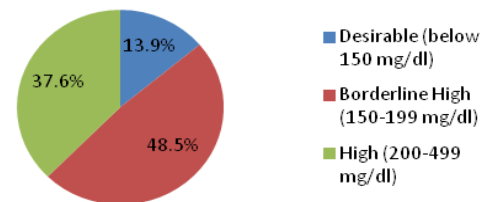

Figure 7 Distribution of participants by TG $(n=100)$.

Data represented in above figure shows $13.9 \%$ were in desirable TG range, $48.5 \%$ were in borderline high range, $37.6 \%$ were in high range.

\section{Distribution of the Calorie Intake (Kcal)}

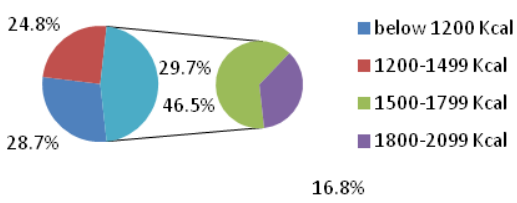

Figure 8 Distribution of participants by Kcal $(\mathrm{n}=100)$.

Figure shows $28.7 \%$ had taken below $1200 \mathrm{kcal}$ followed by $1200-1499 \mathrm{kcal}$ $24.8 \%, 1500-1799 \mathrm{kcal} 29.7 \%$ and $1800-2099 \mathrm{kcal} 16.8 \%$.

\section{Discussion}

The way people eat has changed greatly across the globe; moreover the tendency of change in is quickening in low and middle-income countries. Bangladesh is not escaped from this changing pattern which results full of bed occupancy in cardiovascular hospitals. Evidence suggests that snacking and snack foods have grown in frequency and number; ${ }^{4-9}$ eating frequency has increased; away-from-home-eating in restaurants, in fast food outlets, and from take-out meals is increasing dramatically in low and middle-income countries; both at home and away-from-home-eating increasingly involve fried and processed food; ${ }^{10}$ and the overall proportion of highly processed food in diets has grown. ${ }^{11,12}$ In our day to day life we observe this scenario. Technology dependent life style makes this situation more vivid and complex. The present study found that about one-sixth respondents removed visible fat of meat whereas nearly half of the respondents consumed oily foods about 2-3 times a day. LDL and TG intake are still high among study subjects. Research shows that at very low levels of intake animal food consumption may not induce harm, providing high quality protein and iron, whereas excess animal food intake in high income countries may be linked to adverse health outcomes, particularly from processed meats. ${ }^{13}$ Meat consumption has increased considerably worldwide. ${ }^{14}$ But what about in our country; needs up-to-date data. It is evident based that high consumption of vegetables (leafy and non-leafy) and fruits reduces chronic heart diseases as well as stroke. ${ }^{15}$ We know that vegetable oils appear to reduce chronic heart disease risk. If we replace saturated fat with monounsaturated or polyunsaturated fat which in turn reduces low-density lipoprotein cholesterol and preserves highdensity lipoprotein cholesterol. ${ }^{16}$ Trans-fatty acids increase CHD risk compared with other macronutrients, with strong evidence of adverse effects of small amounts of trans-fats on lipids and CVD risk. ${ }^{17-19}$ 


\section{Conclusion}

Intake of low-density lipoprotein and triglyceride is still high among study subjects. Health awareness programme can be constituted immediately to prevent fatty foods and calorie intake related risk factors of cardiovascular diseases.

\section{Acknowledgements}

None.

\section{Conflict of interest}

The author declares that there is no conflict of interest.

\section{References}

1. Anand SS, Hawkes C, de Souza RJ, et al. Food Consumption and its impact on Cardiovascular Disease: Importance of Solutions focused on the globalized food system. J Am Coll Cardiol. 2015;66(14):15901614 .

2. Lim SS, Vos T, Flaxman AD, et al. A comparative risk assessment of burden of disease and injury attributable to 67 risk factors and risk factor clusters in 21 regions, 1990-2010: a systematic analysis for the Global Burden of Disease Study 2010. Lancet. 2012;380(9859):22242260 .

3. Krauss RM, Eckel RH, Howard B, et al. AHA dietary guidelines, revision 2000: a statement for healthcare professionals from the Nutrition Committee of the American Heart Association. Circulation. 2000;102(18):2296-2311.

4. Adair LS, Popkin BM. Are child eating patterns being transformed globally? Obes Res. 2005;13(7):1281-1299.

5. Duffey KJ, Pereira RA, Popkin BM. Prevalence and energy intake from snacking in Brazil: analysis of the first nationwide individual survey. Eur J Clin Nutr. 2013;67(8):868-874.

6. $\mathrm{Ng} \mathrm{S}$, Zaghloul S, Ali H, et al. Nutrition transition in the United Arab Emirates. Eur J Clin Nutr. 2011;65(12):1328-1337.

7. Popkin BM, Duffey KJ. Does hunger and satiety drive eating anymore? Increasing eating occasions and decreasing time between eating occasions in the United States. Am J Clin Nutr. 2010;91(5):1342-1347.
8. Wang Z, Zhai F, Du S, et al. Dynamic shifts in Chinese eating behaviors. Asia Pac J Clin Nutr. 2008;17(1):123-130.

9. Duffey KJ, Rivera J, Popkin B. Snacking is prevalent in Mexico. $J$ Nutr. 2014;144(11):1843-1849.

10. Monteiro C, Gomes F, Cannon G. The snack attack. Am J Public Health. 2010;100(6):975-981.

11. Monteiro C, Moubarac J, Cannon G, et al. Ultra-processed products are becoming dominant in the global food system. Obes Rev. 2013;14(Suppl 2):21-28.

12. Poti JM, Mendez MA, Ng SW, et al. Is the degree of food processing and convenience linked with the nutritional quality of foods purchased by US households? Am J Clin Nutr. 2015;101(6):1251-1262.

13. Sinha R, Cross AJ, Graubard BI, et al. Meat intake and mortality: A prospective study of over half a million people. Arch Intern Med. 2009;169(6):562-571.

14. Kearney J. Food consumption trends and drivers. Philos Trans $R$ Soc Lond B Biol Sci. 2010;365(1554):2793-2807.

15. Mente A, de Koning L, Shannon HS, et al. A systematic review of the evidence supporting a causal link between dietary factors and coronary heart disease. Arch Intern Med. 2009;169(7):659-669.

16. Mensink RP, Zock PL, Kester AD, et al. Effects of dietary fatty acids and carbohydrates on the ratio of serum total to HDL cholesterol and on serum lipids and apolipoproteins: a meta-analysis of 60 controlled trials. Am J Clin Nutr. 2003;77(5):1146-1155.

17. Brouwer IA, Wanders AJ, Katan MB. Effect of animal and industrial trans fatty acids on HDL and LDL cholesterol levels in humans--a quantitative review. Plos One. 2010;5(3):e9434.

18. Bendsen NT, Christensen R, Bartels EM, et al. Consumption of industrial and ruminant trans fatty acids and risk of coronary heart disease: a systematic review and meta-analysis of cohort studies. Eur J Clin Nutr. 2011;65:773-783.

19. Mozaffarian D, Katan MB, Ascherio A, et al. Trans fatty acids and cardiovascular disease. N Engl J Med. 2006;354(15):1601-1613. 